\title{
The Construction And Study Of The Evaluation Index System For Scientific And Technological Achievements Of Applied Technology
}

\author{
Pengnan Zhang ${ }^{*}$ Keqiang Cheng, Ming Dang, Xiangtao Peng, Tianjiao Liu \\ China Electronic Product Reliability and Environment Testing Research Institute, \\ No.110, Dongguanzhuang Road, Guangzhou, Guangdong, China \\ 87879630@qq.com, ckqjiayou@163.com,305298893@qq.com, pengxiangtao@ceprei.com, \\ liutj@ceprei.org
}

Keywords: achievements of applied technology, evaluation principles, evaluation index

\begin{abstract}
In this paper, the application technology achievement evaluation index system framework is built up based on the analysis of the connotation and characteristics of the scientific and technological achievements of applied technology. By using fuzzy comprehensive evaluation method, the construction of the evaluation index system is carried out, as well as the detailed analysis of the contents and criteria for each index. Experimental results show that the proposed method could be effective in the evaluation for scientific and technological achievements of applied Technology.
\end{abstract}

\section{Introduction}

With the continuous progress of science and technology, it has become an important criterion to measure the independent innovation capability as well as the overall level of technology development for a country or region that whether scientific and technological achievements are converted into practical productivity. The premise and foundation of scientific and technology achievements transformation is the evaluation. Therefore, building up a scientific, reasonable and operable evaluation index system for scientific and technological achievements is of great theoretical and practical significance. The achievements of applied technology occupy a large proportion of scientific and technological achievements in China, and the transformation and application of those could directly affect the economy and society development of our country. In this paper, the basic framework of evaluation index system is constructed based on the construction principles of evaluation index system for application technology. And then the fuzzy comprehensive evaluation method is used to complete the evaluation system.

\section{The connotation and characteristics of the scientific and technological achievements of applied technology}

According to "Tentative Measures for the evaluation of scientific and technological achievements", scientific and technological achievements refer to new discoveries, new theories, new methods and new technology, new products, new varieties and new technology etc., completed by the organization or individual in the projects, with academic value or application value as well as scientific, creative and advanced properties [1]. The scientific and technological achievements could be classified into three categories, which are basic research achievements, applied technology achievements and software science research achievements.

Applied technology achievements mainly refer to those of practical value which are produced by scientific research, technological development, follow-up experiments and application promotion to improve productivity and promote social welfare undertakings. This kind of achievement occupies a considerable proportion in the scientific and technological achievements of our country, the transformation and application of which have a direct impact on the economic and social benefits. 


\section{Design rules and construction of evaluation index system}

\subsection{Design rules for evaluation index}

The construction of the index system needs to conform to the characteristics of the applied technology achievements. Therefore, the following principles should be followed.

1) Scientificalness

The scientific principle is the foundation of establishing the evaluation index system of the applied technology achievement. The evaluation index system should objectively and truly reflect the value and level of scientific and technological achievements.

2) Systematicness

The evaluation index system should be able to totally and completely reflect all aspects of scientific and technological achievements, which not only reflect the comprehensive level of scientific and technological achievements, but also reflect the other different aspects [2].

3) Purposiveness

This principle is to establish the starting point of the evaluation index system for the applied technology achievements. Research on applied technology achievements is a scientific and technological activity that transforms the basic research results into practical application, which has a strong purpose, and could measure the true quality and value.

4) Feasibility

The data and related information of the indicators included in the evaluation index system must be simple and plane, and the calculation of relevant data is evidence-based. The availability of index information as well as the flexibility of execution and the reliability must be taken into consideration when designing the evaluation index system.

\subsection{Construction of evaluation index system}

The frame of the evaluation index system is shown in Figure 1. First of all, the evaluation should be clear according to the characteristics of applied technology achievement [3]. And then the qualitative indicators should be collected and preliminary screened through qualitative method. After that the indicators should be further screened to refine and complete the whole evaluation index system.

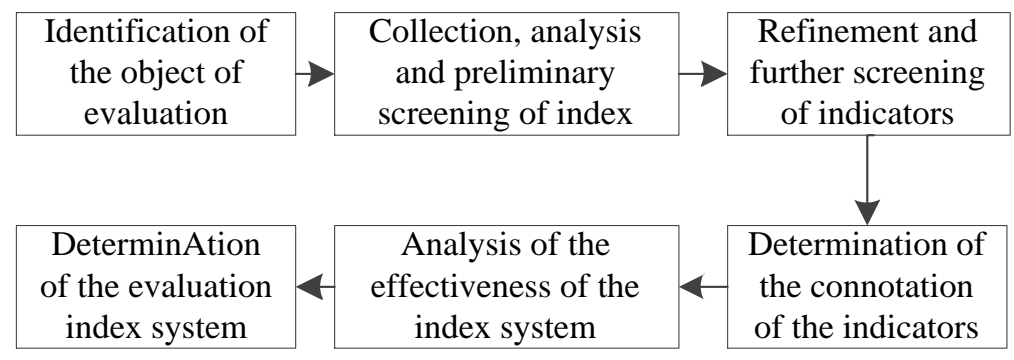

Fig. 1. The frame of the evaluation index system

Combining with applied technology achievement appraisal work of the research institute, and considering the all kinds of factors influencing transformation, a 5 first level indexes with 14 second level indexes evaluation system is proposed, using qualitative and quantitative evaluation method [4].

The index system makes a specific analysis and clear explanation from five aspects: input level, technical level, application, benefits and impacts, and risk. Every index and its meaning are shown in Table 1. At the same time, the method of fuzzy mathematics is adopted to set the weight of each index. The weights can be adjusted according to the characteristics of the technical results and the focus of the evaluation. 
Table 1. The index and its meaning

\begin{tabular}{|c|c|c|c|c|c|}
\hline \multirow{15}{*}{$\begin{array}{c}\text { The } \\
\text { evaluation } \\
\text { for scientific } \\
\text { and } \\
\text { technological } \\
\text { achievements } \\
\text { of applied } \\
\text { technology } \\
E\end{array}$} & First level & Weight & Second Level & Weight & Meaning \\
\hline & \multirow{4}{*}{$\begin{array}{c}\text { Input Level } \\
e_{1}\end{array}$} & \multirow{4}{*}{0.2} & $\begin{array}{c}\text { Funds } \\
e_{11} \\
\end{array}$ & 0.4 & $\begin{array}{l}\text { The cost of a scientific research project } \\
\text { from beginning to completion }\end{array}$ \\
\hline & & & $\begin{array}{c}\text { Manpower } \\
e_{12} \\
\end{array}$ & 0.3 & $\begin{array}{l}\text { The number of researchers joining the } \\
\text { scientific research project }\end{array}$ \\
\hline & & & $\begin{array}{l}\text { Materials } \\
e_{13}\end{array}$ & 0.1 & $\begin{array}{l}\text { Resources used for the research and } \\
\text { development of the scientific research } \\
\text { project, including factory, laboratory, } \\
\text { scientific instrument, equipment, etc. }\end{array}$ \\
\hline & & & $\begin{array}{c}\text { Time } \\
e_{14}\end{array}$ & 0.1 & $\begin{array}{l}\text { The sum of all the effective time invested in } \\
\text { the research project }\end{array}$ \\
\hline & \multirow{3}{*}{$\begin{array}{l}\text { Technological } \\
\text { Level } \\
e_{2}\end{array}$} & \multirow{3}{*}{0.3} & $\begin{array}{l}\text { Innovativeness } \\
e_{21}\end{array}$ & 0.5 & $\begin{array}{l}\text { Some breakthroughs in new technology, } \\
\text { new research methods, design ideas and } \\
\text { technological characteristics, and the } \\
\text { innovation complexity and difficulty degree } \\
\text { of the technical achievements }\end{array}$ \\
\hline & & & $\begin{array}{l}\text { Advancement } \\
e_{22}\end{array}$ & 0.3 & $\begin{array}{l}\text { The international and domestic level } \\
\text { achieved compared with the most advanced } \\
\text { indicators, and Strategy and foresight of } \\
\text { technology }\end{array}$ \\
\hline & & & $\begin{array}{l}\text { Stability and } \\
\text { reproducibility } \\
e_{23}\end{array}$ & 0.2 & $\begin{array}{l}\text { The reliability, the updating frequency, the } \\
\text { degree of renewal and the life cycle of the } \\
\text { technology }\end{array}$ \\
\hline & \multirow{2}{*}{$\begin{array}{l}\text { Application } \\
e_{3}\end{array}$} & \multirow{2}{*}{0.15} & $\begin{array}{l}\text { Applicability } \\
e_{31}\end{array}$ & 0.5 & $\begin{array}{l}\text { The degree of adaptation in social, } \\
\text { scientific, economic and other aspects }\end{array}$ \\
\hline & & & $\begin{array}{c}\text { Market } \\
e_{32}\end{array}$ & 0.5 & $\begin{array}{l}\text { Market demand, occupancy rate, annual } \\
\text { sales and sales trends }\end{array}$ \\
\hline & \multirow{3}{*}{$\begin{array}{l}\text { Benefits and } \\
\text { impacts } \\
e_{4}\end{array}$} & \multirow{3}{*}{0.25} & $\begin{array}{c}\text { Economic } \\
\text { Benifit } \\
e_{41} \\
\end{array}$ & 0.4 & $\begin{array}{l}\text { The actual or expected cost effectiveness } \\
\text { and cost- benefit ratio after using the } \\
\text { achievements }\end{array}$ \\
\hline & & & $\begin{array}{l}\text { Social Benifit } \\
\qquad e_{42}\end{array}$ & 0.3 & $\begin{array}{l}\text { The effect of promoting the coordination of } \\
\text { science and technology, economy and } \\
\text { society and sustainable development }\end{array}$ \\
\hline & & & $\begin{array}{l}\text { Promoting the } \\
\text { research field } \\
e_{43}\end{array}$ & 0.3 & $\begin{array}{l}\text { The impetus of the proposed theory, method } \\
\text { and point of view on the development of the } \\
\text { research field }\end{array}$ \\
\hline & \multirow{2}{*}{$\begin{array}{c}\text { Risk } \\
e_{5}\end{array}$} & \multirow{2}{*}{0.1} & $\begin{array}{c}\text { Technology } \\
\text { Risk } \\
e_{51} \\
\end{array}$ & 0.5 & $\begin{array}{l}\text { Uncertain factors caused by technical } \\
\text { maturity, intellectual property rights and } \\
\text { technical secrets }\end{array}$ \\
\hline & & & $\begin{array}{l}\text { Market Risk } \\
\quad e_{52}\end{array}$ & 0.5 & $\begin{array}{l}\text { The factors such as Whether scientific and } \\
\text { technological achievements are difficult to } \\
\text { enter the market or not, and so on. }\end{array}$ \\
\hline
\end{tabular}

\section{Fuzzy comprehensive evaluation method}

The fuzzy comprehensive evaluation method is based on the theory of fuzzy set theory, which carries out a comprehensive evaluation of the achievement [5].

In this paper, the proposed calculation method of fuzzy comprehensive evaluation method for scientific and technological achievements in applied technology is as follows:

1) Define the evaluation index set $E$ :

2) Determine the rating set $L$ :

$$
E=\left\{e_{1}, e_{2}, \ldots, e_{\mathrm{n}}\right\}
$$

$$
L=\left\{l_{1}, l_{2}, \ldots, l_{\mathrm{m}}\right\}
$$

3) Establish the fuzzy mapping matrix $R$ : 
$R$ is the mapping matrix of the evaluation index $E$ and the fuzzy mapping matrix $R$. The element $R_{\mathrm{ij}}$ represents the probability of the $j$ grade for the evaluated result for the $i$ index.

The fuzzy mapping matrix can be expressed as:

4) Determine the weight of the evaluation index:

$$
R=\left[\begin{array}{cccc}
r_{11} & r_{12} & \ldots & r_{1 \mathrm{~m}} \\
r_{21} & r_{22} & \ldots & r_{2 \mathrm{~m}} \\
\vdots & \vdots & & \vdots \\
r_{\mathrm{n} 1} & r_{\mathrm{n} 2} & \ldots & r_{\mathrm{nm}}
\end{array}\right]
$$

$\left\{W\left(\mathrm{e}_{\mathrm{i}}\right)\right\}(i=1,2, \ldots, n)$, which represent the weight of the evaluation index $e_{\mathrm{i}}$ in $E$. The degree of membership of $e_{\mathrm{i}}$ to $W$ is expressed by $\mathrm{W}\left(e_{\mathrm{i}}\right)$. Generally, set $\mathrm{W}\left(e_{\mathrm{i}}\right)$ as (4):

5) Fuzzy mapping:

$$
\sum_{i=1}^{n} W\left(\mathrm{e}_{\mathrm{i}}\right)=1
$$

The comprehensive evaluation model of fuzzy mapping is $M=W \times R$. Then the comprehensive evaluation could be given according to $M$.

\section{Experimental Results}

The above fuzzy evaluation method is used to evaluate the achievements of a certain achievement. 20 experts in the related field are employed to form an assessment group to evaluate the achievement. The detailed process is as follows:

1) Define the evaluation index set $E$ :

$E=\left\{e_{1}, e_{2}, e_{3}, e_{4}, e_{5}\right\} \quad, \quad e_{1}=\left\{e_{11}, e_{12}, e_{12}, e_{14}\right\} \quad, \quad e_{2}=\left\{e_{21}, e_{22}, e_{23}\right\} \quad, \quad e_{3}=\left\{e_{31}, e_{22}\right\}$, $\mathrm{e}_{4}=\left\{e_{41}, e_{42}, e_{42}\right\}, \mathrm{e}_{5}=\left\{e_{51}, e_{52}\right\}$, which is shown in Table 1.

2) Determine the rating set $L$ :

$L=$ \{excellent, good, mediocre, poor $\}$.

3) Establish the fuzzy mapping matrix $R$ :

According to the statistical analysis and processing of the comments given by 20 experts for each $e_{\mathrm{ij}}$ evaluation index, a fuzzy evaluation matrix is constructed.

For example, for $e_{11}$ in the second level evaluation index of funds, there are 4 expert comments as "excellent", 8 experts comments as "good", 6 experts comment as "mediocre", 2 experts comments as "poor", and then a fuzzy set is $\left(\begin{array}{llll}0.2 & 0.4 & 0.3 & 0.1\end{array}\right)$ for the index on $L$. Therefore, input level $e_{1}$, technological level $e_{2}$, application $e_{3}$, benefits and impacts $e_{4}$, and risk $e_{5}$ are as (5) (9):

$$
\begin{aligned}
\mathrm{R}_{1} & =\left[\begin{array}{lllr}
0.2 & 0.4 & 0.3 & 0.1 \\
0.2 & 0.5 & 0.3 & 0 \\
0.1 & 0.6 & 0 & 0.3 \\
0.5 & 0.3 & 0.2 & 0
\end{array}\right] \\
\mathrm{R}_{2} & =\left[\begin{array}{cccc}
0.3 & 0.1 & 0.2 & 0.4 \\
0.1 & 0 & 0.5 & 0.4 \\
0.3 & 0.2 & 0.4 & 0.1
\end{array}\right] \\
\mathrm{R}_{3} & =\left[\begin{array}{cccc}
0.5 & 0.3 & 0.2 & 0 \\
0.3 & 0.2 & 0.5 & 0
\end{array}\right] \\
\mathrm{R}_{4} & =\left[\begin{array}{cccc}
0.6 & 0.4 & 0 & 0 \\
0.5 & 0.5 & 0 & 0 \\
0.4 & 0.5 & 0.1 & 0
\end{array}\right] \\
\mathrm{R}_{5} & =\left[\begin{array}{llll}
0.3 & 0.4 & 0.2 & 0.1 \\
0.6 & 0.4 & 0 & 0
\end{array}\right]
\end{aligned}
$$

4) The weight matrix for each index:

The weight matrix of first index is $W=\left[\begin{array}{lllll}0.2 & 0.3 & 0.15 & 0.25 & 0.1\end{array}\right]$. 
The weight matrixes for second index are $W_{1}=\left[\begin{array}{llll}0.4 & 0.3 & 0.1 & 0.1\end{array}\right], W_{2}=\left[\begin{array}{lll}0.5 & 0.3 & 0.2\end{array}\right]$, $W_{3}=\left[\begin{array}{ll}0.5 & 0.5\end{array}\right], W_{4}=\left[\begin{array}{lll}0.4 & 0.3 & 0.3\end{array}\right], W_{5}=\left[\begin{array}{ll}0.5 & 0.5\end{array}\right]$.

5) Fuzzy evaluation for second level index:

The fuzzy evaluation for second level index can be expressed by (10) (14)

$$
\begin{aligned}
\mathrm{M}_{1} & =\mathrm{W}_{1} \times \mathrm{R}_{1}=\left[\begin{array}{llll}
0.20 & 0.40 & 0.23 & 0.07
\end{array}\right] \\
\mathrm{M}_{2} & =\mathrm{W}_{2} \times \mathrm{R}_{2}=\left[\begin{array}{llll}
0.24 & 0.09 & 0.33 & 0.34
\end{array}\right] \\
\mathrm{M}_{3} & =\mathrm{W}_{3} \times \mathrm{R}_{3}=\left[\begin{array}{llll}
0.40 & 0.16 & 0.35 & 0
\end{array}\right] \\
\mathrm{M}_{4} & =\mathrm{W}_{4} \times \mathrm{R}_{4}=\left[\begin{array}{llll}
0.51 & 0.46 & 0.03 & 0
\end{array}\right] \\
\mathrm{M}_{5} & =\mathrm{W}_{5} \times \mathrm{R}_{5}=\left[\begin{array}{llll}
0.45 & 0.40 & 0.10 & 0.05
\end{array}\right]
\end{aligned}
$$

6) Final fuzzy evaluation:

From the calculations above, the fuzzy evaluation matrix of this achievement is $\mathrm{R}=\left[\begin{array}{lllll}M_{1} & M_{2} & M_{3} & M_{4} & M_{5}\end{array}\right]^{T}$. With the weight matrix of first index $\mathrm{W}=\left[\begin{array}{lllll}0.2 & 0.3 & 0.15 & 0.25 & 0.1\end{array}\right]$, the final evaluation matrix can be figured out:

$$
\begin{aligned}
& \mathrm{M}=\mathrm{W} \times \mathrm{R}=\left[\begin{array}{lllll}
0.2 & 0.3 & 0.15 & 0.25 & 0.1
\end{array}\right] \times \\
& {\left[\begin{array}{llll}
0.20 & 0.40 & 0.23 & 0.07
\end{array}\right]} \\
& \begin{array}{llll}
0.24 & 0.09 & 0.33 & 0.34
\end{array} \\
& \begin{array}{llll}
0.40 & 0.16 & 0.35 & 0
\end{array} \\
& \begin{array}{llll}
0.51 & 0.46 & 0.03 & 0
\end{array} \\
& {\left[\begin{array}{llll}
0.45 & 0.40 & 0.10 & 0.05
\end{array}\right]} \\
& {\left[\begin{array}{llll}
0.3445 & 0.346 & 0.215 & 0.121
\end{array}\right]}
\end{aligned}
$$

After the above calculation, the maximum value of the final matrix $M$ is taken, and the final evaluation level of this achievement is "good".

According to the corresponding index in Table 1, for further analysis, the assessment of the investment level is "good", which means that it is of good cost control. Technology level assessment is "poor", which means that it needs further enhancement. Benefits and effects assessment is "excellent", which means that it is of good economic and social benefits. Risk assessment is "good".

In the above fuzzy evaluation method of scientific and technological achievements, the levels granularity can be divided more finely, and the weight of all levels of indicators could be adjusted according to different concerns.

\section{Summary}

In this paper, a fuzzy mathematics comprehensive evaluation method is proposed to construct the evaluation index system for applied technology achievements, from a theoretical point of view. It could play a guiding role, and meet the demands of evaluation for applied technological achievements.

\section{References}

[1] Kou Yuanhu, Tao Rui, Research on Evaluation Index System and Evaluation Criterion of National Defense Scientific and Technological Achievements, Scientific Management Research, vol. 33, pp. 32-34, 2015.

[2] Chen Hongmei, Xiong Siyong, Research on the Evaluation Index System for Applied Technical Achievements, Science and Technology Management Research, vol.8, pp. 35-37, 2001.

[3] Yuan Jie, Yuan Ruhua, Design and Application Research on Evaluation Index System of Water conservancy Sci-Tech Achievements, Journal of Chongqing University of Technology(Natural Science), vol. 30, pp.134-139, 2016.

[4] Yuan Ruili, Comprehensive Research on Assessment of Applied Technical Achievements Based on DEA, Master Dissertation, Qingdao University, 2014. 
[5] Guo Wei, Zhao Jie, Cao Ran, Research on Scientific and Technological Achievements Value Evaluation System of Agricultural Applied Technology-Basing on the Fuzzy Comprehensive Evaluation Method, Journal of Agricultrual Mechanization Research, vol.1, pp. 60-63, 2012. 